\title{
Performance of Small CST Column Gas Generation Test in Radiation Field
}

by

R. Jones

Westinghouse Savannah River Company

Savannah River Site

Aiken, South Carolina 29808

R. A. Jacobs

K. J. Rueter

J. T. Carter

This paper was prepared in connection with work done under the above contract number with the U.S. Department of Energy. By acceptance of this paper, the publisher and/or recipient acknowledges the U.S. Government's right to retain a nonexclusive, royalty-free license in and to any copyright covering this paper, along with the right to reproduce and to authorize others to reproduce all or part of the copyrighted paper. 


\section{DISCLAIMER}

This report was prepared as an account of work sponsored by an agency of the United States Government. Neither the United States Government nor any agency thereof, nor any of their employees, makes any warranty, express or implied, or assumes any legal liability or responsibility for the accuracy, completeness, or usefulness of any information, apparatus, product or process disclosed, or represents that its use would not infringe privately owned rights. Reference herein to any specific commercial product, process or service by trade name, trademark, manufacturer, or otherwise does not necessarily constitute or imply its endorsement, recommendation, or favoring by the United States Government or any agency thereof. The views and opinions of authors expressed herein do not necessarily state or reflect those of the United States Government or any agency thereof.

This report has been reproduced directly from the best available copy.

Available for sale to the public, in paper, from: U.S. Department of Commerce, National Technical Information Service, 5285 Port Royal Road, Springfield, VA 22161, phone: (800) 553-6847, fax: (703) 605-6900 email: orders@ntis.fedworld.gov online ordering: http://www.ntis.gov/ordering.htm

Available electronically at http://www.doe.gov/bridge

Available for a processing fee to U.S. Department of Energy and its contractors, in paper, from: U.S. Department of Energy, Office of Scientific and Technical Information, P.O. Box 62, Oak Ridge, TN 37831-0062, phone: (865)576-8401, fax: $(865) 576-5728$ email: reportseadonis.osti.gov 


\section{DISCLAIMER}

Portions of this document may be illegible in electronic image products. Images are produced from the best available original document. 
HLW-SDT-99:0257

Revision: 0

\section{SAVANNAH RIVER SITE}

\section{HIGH LEVEL WASTE SALT DISPOSITION \\ SYSTEMS ENGINEERING TEAM}

POSITION PAPER

$\mathrm{ON}$

\section{PERFORMANCE OF SMALL CST COLUMMN GAS GENERATION TEST IN RADIATION FIELD}

APPROVED: Kobrey W. Blademor for

DATE: $8 / 26 / 99$

K. J. Rueter: Director of Engineering HLW Salt Disposition

APPROVED:\%メIAt for

S. F. Piccolo: Program Manager HLW Salt Disposition

DATE: $8 / 31 / 99$ 
HILW-SDT-99-0257

Revision: 0

Page 2 of 16

\subsection{PURPOSE}

The purpose of this position paper is to describe the circumstances leading to the decision to delete the dynamic CST small column radiolytic gas generation test from the current phase of tests and the impact of that decision on the Decision Phase.

\subsection{CONCLUSIONS}

2.1 Gas will be generated by radiolysis in excess of the liquid solubility in a 16 $\mathrm{ft}$ long, fully Cs-loaded CST bed. The current data does not:provide sufficient insight to determine whether the mass transfer within the CST particles may be affected.

2.2 Data on the affect of bubble formation on column hydraulics (e.g., channeling, pressure drop) is expected to be provided by the gas generation experiments in the $16 \mathrm{ft}$ tall $\times 3$ in diameter CST column at ORNL. During the selection phase, the Risk Assessment for the effect of gas generation on column hydraulics will be adjusted accordingly based on the results of this test.

2.3 Due to a combination of technical limitations, timing, and resources, the dynamic CST small column radiolytic gas generation test cannot be performed in a timely manner to provide information for the Alternate Salt Disposition Decision Phase. Insight into intraparticle effects has been provided by the real waste CST column test. The manufacturer of the engineered CST has stated that even if gas were to form within the particles, there would be sufficient liquid film remaining in the pores to facilitate the Cs mass transfer to the active ion exchange sites. Based on this information, this new risk (not identified during Phase III) will be assigned a "zero" risk and therefore will not impact the decision phase.

2.4 Taken in its entirety, the gas genieration program will produce significant additional information not available during the Phase III deliberations. Overall, the uncertainty associated with this issue should be significantly reduced.

\subsection{BACKGROUND}

In the current phase of the Alternative Salt Disposition process (the Decision Phase), further experimental work is proceeding on the three processes still under consideration: Small Tank TPB Precipitation, CST Non-Elutable Ion Exchange, and Direct Disposal in Grout. The experimental work is aimed specifically at producing key information to reduce the uncertainty/risk for each alternative; thus providing the basis for a clear choice 
among the alternatives. The experimental work authorized during the Decision Phase, and the logic for using the information developed, is documented in Reference 1.

During Phase III, it was recognized that the lead CST column ( $16 \mathrm{ft}$ bed, $5 \mathrm{ft}$ diameter) is expected to accumulate large quantities of ${ }^{137} \mathrm{Cs}$ - upwards to $3.7 \mathrm{M} \mathrm{Ci}$.[2] The quantity will be even greater since the granular dilution factor is $\sim 1 .[3]$ This quantity of ${ }^{137} \mathrm{Cs}$ in a relatively small, confined space presents significant engineering challenges for removal of decay heat and generation of radiolytic gases (hydrogen and oxygen). Specifically, one of the concerns is with generation of gas bubbles both in the bulk bed and inside the CST particle. Under flowing conditions, bubbles in the bed could lead to increased pressure drop/column "blinding" and flow channeling while intraparticle gas could interfere with ${ }^{137} \mathrm{Cs}$ adsorption or lead to excessive particle attrition. Either or both could cause early ${ }^{137} \mathrm{Cs}$ breakthrough, reduced cycle times, increased CST consumption and excessive CST in the DWPF glass. At current estimated CST production rates, increase of $50 \%$ in the CST produced would lead to increased glass production. Under non-flowing conditions, a flammable gas mixture would accumulate in the column and the aqueous solution would be pushed out of the column with possible column pressurization:

The Decision Phase Scope of Work [1] identified the need to obtain information on gas generation in a CST bed (Item 9.1). A Task Technical Request (TTR) was submitted to SRTC requesting this work. [4] The tasks requested were:

- 9.1.1 Using available information, calculate the radiolytic rate of formation of gases and predict potential effects on column performance. Review calculations with persons experienced in radioactive IX column operation and identify additional data needed to improve calculations.

- 9.1.2 Irradiate static columns loaded with CST resin and appropriate simulant compositions that favor gas formation at ambient pressure. Dose rate should approximate that of a loaded column $(\sim 1 \mathrm{Mrad} / \mathrm{hr})$. If bubbles are observed, determine if increasing the pressure (up to $1 \mathrm{~atm}$ gauge) prevents bubbles from forming.

- 9.1.3 Using CST slurries with simulants, determing G-value for $\mathrm{H} 2$ and $\mathrm{O} 2$ production. Check for other gases and determine G-Values. Determine the effect of salt solution composition, dose rate and total dose on G-values for various gases observed.

- 9.1.4 Using simulants and tracers, determine the effect of radiation on CST capacity or kinetics in small column tests. For column tests in radiation field, monitor for formation of gas bubbles under flowing conditions.

Two additional experimental programs are relevant to the gas generation work: (1) "Tall column" studies at Oak Ridge National Laboratory, and (2) the real waste CST column test at SRTC. 
- The Task Technical Plan (TTP) for the tall column studies (3 in diameter $\times 16 \mathrm{ft}$ tall) at ORNL (HLW-SDT-TTR-10.0) includes the objective to observe how gases introduced to the column are retained and disengaged.[5]

- The real waste CST test (HLW-SDT-TTR-99-09.2) involves loading Cs onto CST in a column from an actual waste solution. This test may provide some insights into gas generation.

\subsection{DISCUSSION}

\subsection{Status of gas generation program}

\subsubsection{Estimate of gas generation}

SRTC prepared a Task Technical Plan (TTP) which included a task to estimate gas formation rates in a full size column and to run a small column test in a radiation field.[6] Walker's calculations are shown in Attachment 1 . He concludes that in a column loaded with Cs, the oxygen generation rate from a salt solution will exceed the solubility limit of the flowing stream by about a factor of two - even if the feed initially contain no dissolved gases. He also concludes that in a stagnant column, the gas generation would exceed the solubility in the salt solution in about $1 / 2$ hour - again assuming the initialcontains no dissolved gas.

\subsubsection{Static column irradiation}

Two static CST beds immersed in $0.1 \mathrm{M} \mathrm{NaOH}$ and $5.6 \mathrm{M}$ simulated salt solutions were irradiated in the cobalt well $(\sim 1 \mathrm{Mrad})$. Bubble . formation was noted in about 8 hours. The beds expanded as the bubbles accumulated. Bed expansion of approximately $15-20 \%$ was observed.

\subsubsection{G value determinations}

Two solution compositions with and without CST present were irradiated at two dose rates. The tests are complete and analyses are in progress.

Tests performed during Phase III showed the presence of CST does not enhance the rate of $\mathrm{H} 2$ generation from a simulated salt solution.[7] 


\section{4:1.4 Flowing small column in a radiation field}

For the flowing test in a radiation field, the TTP[6] describes a dynamic small column test in a SRTC cobalt well. This would be a $1.5 \mathrm{~cm}$ diameter by $10 \mathrm{~cm}$ long column with salt solution flowing at 5 $\mathrm{cm} / \mathrm{min}$ - which is somewhat faster than the nominal design rate of $4.1 \mathrm{~cm} / \mathrm{min}$. A high nitrate salt solution would be used because it would generate the most gas per unit volume. The column would be exposed in the cobalt well to a $1 \mathrm{Mrad} / \mathrm{hr}$ radiation field which is approximately double that calculated for a fully loaded column. The Cs breakthrough curve would be monitored and compared to the predicted curve to determine if gas generation affected column performance. Periodically, personnel would pull the column from the cobalt well and visually monitor the column for bubble formation and impact on column flow.

At the June 7, 1999 SRTC Plan of the Week meeting, SRTC presented for review and discussion the final proposed test conditions for the dynamic CST column radiolytic gas generation test:

- $1.5 \times 10 \mathrm{~cm}$ long column (compare to other tests)

- $5 \mathrm{~cm} / \mathrm{min}$ superficial velocity (approximately the same as plant design)

- high nitrate salt solution (maximum gas production)

- $\sim 1 \mathrm{Mrad} / \mathrm{hr}$ dose rate

- operate to $95 \%$ breakthrough ( $\sim 9$ days)

During the course of the discussion, it was recognized that at the proposed superficial velocity and bed length the salt solution would be exposed to the radiation field for only a short time. In fact, the residence time in the bed would be less than in a fully loaded $16 \mathrm{ft}$ bed by a factor of $\sim 50(16 \mathrm{ft} / 10 \mathrm{~cm})$; that is, about 1.25 minutes in the $10 \mathrm{~cm}$ column as compared to about 60 minutes in the plant column. The total dose would be equivalent to about 2.5 minutes in the column - or about $1 / 25$ of the total dose received in the fully loaded column. Therefore, the salt solution would not receive a radiation dose sufficient to exceed the solubility limit and produce gas bubbles. At subsequent meetings (June 14 and June 30), a number of alternative test methods were presented and discussed (see Section 4.3).

\subsubsection{Gas generation in tall column}

Tall column tests are being performed at ORNL to study column hydraulics. A 3 inch diameter by $16 \mathrm{ft}$ long column is being used to study column loading, unloading, pressure drop under flowing 
conditions, and the effect of gas generation on column operation. Preparations for the gas tests are nearing completion. It has been determined that $\mathrm{O} 2$ will be generated in-situ (at the molecular level) by the decomposition of hydrogen peroxide mixed with the salt solution simulant. Preparations include determining the peroxide concentration required to produce $\mathrm{O} 2$ rates comparable to estimates. Preliminary tests indicate most of the $\mathrm{O} 2$ will be generated within the CST bed itself. Simulant flow rate will be the same as current plant design.

\subsubsection{Real waste test}

Radioactive waste (5.4M Na+) containing $1.7 \mathrm{Ci} / \mathrm{gal}$ was passed through a $1.5 \mathrm{~cm}$ diameter $\mathrm{x} 160 \mathrm{~cm}$ long column at $5.3 \mathrm{~cm} / \mathrm{min}$ superficial velocity for $51 / 2$ days. Cs concentrations (i.e., performance) as a function of time were approximately nominal at 10 $\mathrm{cm}$ into the column and somewhat better than expected at $85 \mathrm{~cm}$ and $160 \mathrm{~cm}$ with a residence time of approximately $40 \%$ of the current plant design. No bubble formation was observed under flowing conditions. The first $10 \mathrm{~cm}$ was run to $>95 \%$ breakthrough. Flow has been stopped and bubble formation observed in the first 25 to $30 \mathrm{~cm}$ of the column. The gas generation rate from the static column appears to agree well with the rate predicted based on measured $G$ values and an assumed value for radiation leakage of $75 \%$ from the small diameter equipment.

\subsection{Test Method Attributes for Gas Generation in a Flowing Column}

Ideally, the attributes of a test would be:

- the salt solution would accumulate a total dose of about $0.5 \mathrm{Mrad}$ as it passed through the bed

- the velocity would be comparable to the plant; a very low velocity might allow bubbles to accumulate to such size that they would rise disrupting the bed or causing excessive pressure drop and/or channeling; whereas at plant velocities, microbubbles might be swept from the bed as they are formed

- the gas would be generated at the molecular level by radiolysis; this would ensure the bubbles are formed at the appropriate rate and size

- the test would allow evaluation of both interparticle (macro) and intraparticle (micro) effects; this can only be achieved by radiolysis

- the time to achieve $95 \%$ breakthrough would be reasonable - days or weeks, not months

With regard to assessing maicro effects, the tall column gas generation test at ORNL meets several of the desired attributes. It produces gas at the 
HLW-SDT-99-0257

Revision: 0

Page 7 of 16

molecular level at a fluid velocity comparable to the plant and in a $16 \mathrm{ft}$ long column. It is expected this experiment will yield considerable information on potential macro/hydraulic effects. During the selection phase, the Risk Assessment for the effect of gas generation on column hydraulics will be adjusted accordingly based on the results of this test.

The flowing column in a radiation field and the real waste test have the potential to provide information on the micro (intraparticle) effects. Intraparticle gas would likely be generated in these tests. However, the bulk fluid will not be saturated. This could cause the intraparticle gas to diffuse into the bulk fluid before it builds to a high enough level to impact mass transfer. These tests might provide a "one-sided" result. That is, if performance was poor, one could be sure there is a micro problem. But if performance is as expected, it could not be concluded there is no mircro problem.

\subsection{Test Alternatives Considered}

Several test alternatives were suggested and qualitatively evaluated against the desired test attributes.

Tests that have the poteritial to be performed in the SRTC cobalt well:

4.3.1 Reduce flow rate by $\sim 25 \mathrm{X}$. This alternative would produce the desired radiation exposure and bubble formation. Micro effects should be representative but the velocity would be so slow that the macro effects could be unrepresentative. Also, it could take months to reach $95 \%$ breakthrough.

4.3.2 Increase column length by $\sim 25 \mathrm{X}$. This alternative would meet most of the desired attributes; however, it could not be made to fit in the cobalt well and the time to achieve $95 \%$ breakthrough could be months.

4.3.3 Increase dose rate by $\sim 25 \mathrm{X}$. This is not feasible.

4.3.4 Pre-saturate the feed with oxygen. The $1.5 \mathrm{~cm} \mathrm{x} 10 \mathrm{~cm}$ column would be operated at the design flow rate with a residence time of about 1.25 minutes. The feed would be saturated with $\mathrm{O}_{2}$ by bubbling $\mathrm{O}_{2}$ through the feed. As estimated in Attachment $\mathrm{A}$, the salt solution in a fully loaded column would become saturated about half way through the column with an approximately equivalent amount produced in the rest of the column. In this alternative, only about $8 \%$ of the gas in excess of saturation would be generated in the column itself. This may be insufficient to observe any macro effects, although micro effects should be 
evident. In addition, it was. judged that assuring saturated feed would be very difficult. If the feed were only $8 \%$ below saturation, bubbles would not form at all. Also, the pressure would increase going through the column, thus increasing the gas solubility and further reducing the tendency to form bubbles.

4.3.5 Install feed delay reservoir. This is similar to the previous alternative except the gas would be generated by radiolysis of feed held up in a reservoir preceding the column. The reservoir would have sufficient holdup time to provide the full radioactive dose. This alternative would have the same problems associated with 4.3.4. Other problems include: (1) difficulty assuring saturation due to backmixing in the reservoir - this could be solved by a long, plug flow tube, and (2) preventing release of some of the radiolytically formed gases from the reservoir vent. If the reservoir were sealed to prevent gases from being released prematurely, the reservoir could fill up with gases causing entrainment of bubbles and potentially blinding the bed in a fashion not representative of the process.

4.3.6 Upflow, low velocity. This proposed alternative would be the same as 4.3.1 except that flow would be upwards to prevent excessive accumulation of bubbles. This would show micro effects but would not be expected to elucidate macro effects. Like 4.2.1, it would take months to obtain $95 \%$ breakthrough. Also, it was judged there was a reasonably high risk that excessive bubble accumulation would occur at the reduced velocities even in the upflow. configuration.

4.3.7 Recycle the salt solution. In this alternative, the salt solution would be continuously recycled providing saturated feed to the column. This alternative is similar to 4.3 .4 and 4.3.5 and has many of the same problems. Only $\sim 4 \%$ of gas in excess of solubility would be produced during the pass through the bed. Any bubbles exiting the bottom of the column would tend to accumulate in the high point of the system and eventually cause a vapor lock unless vented. Since Cs would be removed in each pass, a control column without an applied field would be needed to assess any impact on performance.

Other alternatives considered:

4.3.8 Thermal gas generation. This alternative would not require use of a radioactive source. An $\mathrm{O}_{2}$-saturated salt solution would be fed through a column surrounded by a heating device. Dissolved gas would be evolved from the solution since the solubility of gases 
Revision: 0

Page 9 of 16

decreases with increasing temperature. Controlling the location of bubble formation and the potential for non-uniform formation across the radial dimension represent significant challenges to this approach.

4.3.9 Locate higher dose rate gamma source. A check of other sources in the complex revealed: PNNL with 0.2 and $1.0 \mathrm{Mrad} / \mathrm{hr}$, $\mathrm{ANL}$ with $0.6-0.7 \mathrm{Mrad} / \mathrm{hr}$, and ORNL, with $10 \mathrm{Mrad} / \mathrm{hr}$. The source at Oak Ridge is the High Flux Isotope Reactor (HFIR). A test in this reactor would require a combination of higher radiation flux with longer residence time (longer column and/or slower flow rate).

4.3.10 Model gas generation. This approach could be used to estimate where in the column bubbles would form as a function of time; i.e., Cs loading. Such information would be useful in estimating the location and quantity of gas formed. However, it would reveal nothing about micro effects.

\subsection{Test Decision}

At the June 30 meeting, the test in ORNL's HFIR was rated as having the lowest risk of failure with the upflow, low velocity test as second lowest risk. The CST recovery plan indicated the schedule for the upflow test was restrictive (excessive time for breakthrough) and recommended a higher dose, lower flow rate test at another DOE site.[8] Further investigation of the HFIR revealed (see Attachment 2 for more details): no temperature control of the chamber; a field of $10 \mathrm{Mrad} / \mathrm{hr}$ maximum at a point in the chamber center; the requirement of two liquid flow loops passing into and out of the chamber (and into and out of the reactor pool) - one for the salt solution and one for a cooling loop; "grave consequences" of leakage of either the salt solution or coolant; stringent oversight required by the reactor review committee with extensive full-time coverage during the experiment; concurrence from other HFIR customers to permit the needed priority for this experiment.

\subsection{Impact on CST Program}

Preliminary estimates indicate a substantial quantity of gas of in excess of solubility will be generated in a fully loaded, $16 \mathrm{ft}$ CST bed at design residence times. There is uncertainty on the impact of this generation, both intraparticle (mass transfer) and interparticle (column hydraulics). During the decision phase, a dynamic small-scale CST column test in a radiation field was intended to provide some insight into the effects of gas generation on column performance - both micro and macro: However, technical limitations 
related to proper scaling (dose rate, total dose, column length, velocity, gas generation rate and quantity, hydraulics, test duration) make such a test impractical.

Taken in its entirety, the gas generation program will produce significant additional information not available during the Phase III deliberations. The tall column tests are expected to provide a good assessment -of potential hydraulic impacts. The real waste test has provided limited, "one-sided" insight into the impact of intraparticle gas generation on mass transfer. Overall, the uncertainty associated with this issue should be significantly reduced. The risk for macro effects will be adjusted based on tall column test results. The risk for micro effects will be added and set to zero.

\subsection{ATTACHMENTS}

5.1 D. D. Walker's gas generation estimates

5.2 Memorandum from A. Mattus on use of ORNL's HFIR reactor for gas generation study

\subsection{REFERENCES}

1. HLW-SDT-99-0009, Rev. 1, Applied Technology Integration Scope of Work Matrix for Decision Making (Small Tank TPB Precipitation, CST NonElutable Ion Exchange \& Direct Disposal as Grout, January 22, 1999.

2. S. Beck, et al., Bases, Assumptions, and Results of the Flowsheet Calculations for the Short List Salt Disposition Alternatives, WSRC-RP-98-00168, Rev. 1, October 1998.

3. D. D. Walker, et al., Cesium Removal from Simulated SRS High Level Waste Using Crystalline Silicotitanate, WSRC-TR-98-00344, Rev ? 1998. R2v.1 , 12/11/98 $10 / 15$ ort

4. HLW-SDT-TTR-99-09.1, Rev. 0, Ion Exchange Column Tests to Reflect Effects of Radioactive Waste, January 29, 1999.

5. T. D. Welch, Technical Task Plan for CST Tall Column Hydraulic and Gas . Tests, ORNL/CF-99/3, Rev. 0, March 5, 1999.

6. D. D. Walker, Task Technical and Quality Assurance Plan for Non-Elutable Ion Exchange Process Gas Generation Tests, WSRC-RP-99-00189, Rev. 0, February 1999. 
7. N. E. Bibler, et al., Results of Scoping Studies for Determining Radiolytic Hydrogen Production from Moist .CST and CST Slurries, WSRC-RP-9801143, October 2, 1998.

8. D. D. Walker, Recovery Plan for the Non-Elutable Ion Exchange Salt Alternative, WSRC-RP-99-00568, Rev. 0, July 1999. 


\subsection{ATTACHMENT 1}

\section{Radiolytic Gas Generation Calculation}

Case 1. Fully loaded column, no feed flow

Assumptions: IONSIV IE-911 is loaded to $100 \%$ of capacity

Average salt solution composition at $5.6 \mathrm{M} \mathrm{Na}+$

Temperature $=25^{\circ} \mathrm{C}$

Column adsorbs $100 \%$ of Cs-137 decay energy ( 4.95 watts $/ \mathrm{kCi}$ )

No other radionuclides contribute significantly to dose rate. Decay energy deposited in IONSIV IE-911 solids does not generate gas; energy deposited in aqueous phase (including macrochannels of IONSIV IE-911) generates hydrogen and oxygen gas in amounts defined by $\mathrm{G}$ values.

Salt solution composition
$\mathrm{Na}^{+}$
$5.6 \mathrm{M}$
$\mathrm{NO}_{3}^{-}$
2.14 molar
$\mathrm{NO}_{2}^{-}$
0.52 molar
Cs (total)
0.00014 molar
Cs-137
22.5 atom \% of total cesium

IONSIV IE-911 Cs loading capacity

From R. A. Jacobs, WSRC-RP-98001051, Table 4

(note: this loading capacity is based on the TAMU model for powdered

CST and does not include a "dilution" factor for IONSTV IE-911)

At $0.00014 \mathrm{M}$ Cs in the effluent salt solution $(C=0.14$ mmolar), then the concentration of cesium on the CST is $0.2 \mathrm{mmol} / \mathrm{g}(\mathrm{Q}=0.2 \mathrm{mmol} \mathrm{Cs} / \mathrm{g}$

CST). Converting this to curies of Cs-137 per gram of CST:

$$
\begin{aligned}
& 0.2 \frac{\mathrm{mmol}}{\mathrm{g}} * 133 \frac{\mathrm{g}}{\mathrm{mol}} * \frac{1 \mathrm{~mol}}{1000 \mathrm{mmol}}=0.0266 \frac{\mathrm{g} \mathrm{Cs}}{\mathrm{g} \mathrm{CST}} \\
& 0.0266 \frac{\mathrm{gCs}}{\mathrm{gCST}} * 0.225 \frac{\mathrm{g} \mathrm{Cs} 137}{\mathrm{~g} \mathrm{Cs}} * 86.75 \frac{\mathrm{CiCs} 137}{\mathrm{~g} \mathrm{Cs} 137}=0.52 \frac{\mathrm{CiCs} 137}{\mathrm{gCST}}
\end{aligned}
$$

Curies per liter of column

Density of dry packed column is $\sim 1 \mathrm{~kg}$ dry IONSIV IE-911 per L of column. Then:

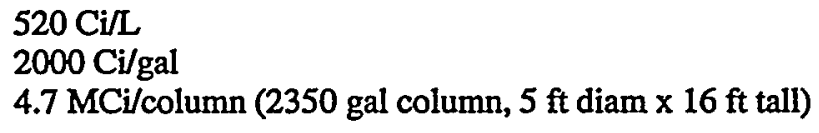

Column occupancy:

Given that a dry packed column has a density of about $1 \mathrm{~g} / \mathrm{mL}$ and the particle density of IONSIV IE-911 is about $2 \mathrm{~g} / \mathrm{mL}$ (note: this . includes the macrochannels as part of the particle volume), then. the void fraction (between particles) is 0.5 and particle fraction is 0.5 . The IONSIV IE-911 particle has a void fraction of 0.24 in the 
form of macrochannels. The actual solid phase density of IONSIV IE-911 (excluding the macrochannels) is about $2.6 \mathrm{~g} / \mathrm{mL}$. Thus, in one liter of column filled with IONSIV IE-911 and salt solution, there is:

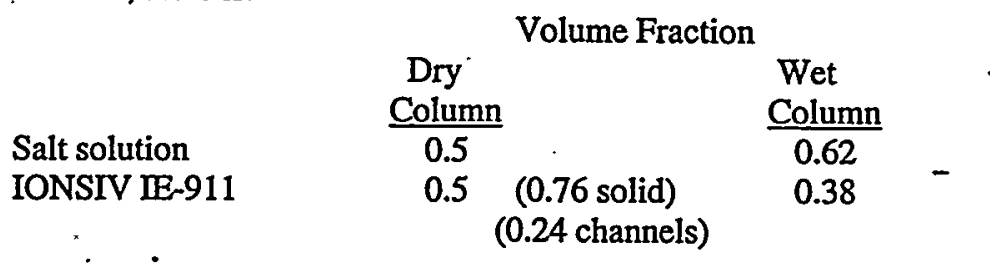

Dose fraction to liquid phase

Assume the dose is distributed in both the aqueous and solid phases in proportion to their mass. Salt solution has a density of $1.26 \mathrm{~g} / \mathrm{mL}$ and IONSIV IE-911 (solid phase) has a density of $2.6 \mathrm{~g} / \mathrm{mL}$.

Dose fraction to liquid $=\frac{0.62 * 1.26}{(0.62 * 1: 26)+(0.38 * 2.6)}=0.44$

Dose to solution in column

Assume no decay energy escapes the volume. For a full column:

$$
\begin{aligned}
\text { Dose rate }(\mathrm{eV} / \mathrm{sec})= & 4.7 \times 10^{6} \mathrm{Ci} * 4.95 \frac{\text { watts }}{10^{3} \mathrm{Ci}} * \frac{1 \mathrm{eV} / \mathrm{sec}}{1.602 \times 10^{-19} \text { watts }} \\
& =1.45 \times 10^{23} \mathrm{eV} / \mathrm{sec}
\end{aligned}
$$

Dose to liquid phase $=(.44)\left(1.45 \times 10^{23} \mathrm{eV} / \mathrm{sec}\right)=6.4 \times 10^{22} \mathrm{eV} / \mathrm{sec}$

Gas generation rates

The $G$ value for hydrogen production is a function of the nitrate and nitrite concentration (see WSRC-TR-96-0109 for G values of hydrogen as a function of nitrate and nitrite). Nitrate $(2.14 \mathrm{M})$ plus $1 / 2$ nitrite $(1 / 2 \times 0.52 \mathrm{M})$ is 2.4 molar. The expected $\mathrm{G}$ value is 0.05 molecules $/ 100 \mathrm{eV}$.

In solutions containing high nitrate concentrations, oxygen is produced at 5 to 6 times the rate of hydrogen (see Hobbs, Norris, Pucko, Bibler, Walker, and d'Entremont, Proceedings of Waste Management '92, Vol.1, p1063, "Hydrogen Generation Rates in Savannah River Site High-Level Nuclear Waste"). The estimated G value is 0.3 molecules $/ 100 \mathrm{eV}$.

Sum of gases is $(0.3+.05)=0.35$ molecules $/ 100 \mathrm{eV}$.

Gas generation rate is:

$$
0.35 \frac{\text { molecules }}{100 \mathrm{eV}} * 6.4 \times 10^{22} \frac{\mathrm{eV}}{\mathrm{sec}} * \frac{24.46 \mathrm{~L} \text { of gas }}{6.022 \times 10^{23} \text { molecules }} * 3600 \frac{\mathrm{sec}}{\mathrm{hr}}=33 \mathrm{~L} / \mathrm{hr}
$$

(note: this is composed of $4.7 \mathrm{~L} / \mathrm{h}$ of $\mathrm{H}_{2}$ and $28.3 \mathrm{~L}^{-} \mathrm{h} \mathrm{O}_{2}$ )

Gas solubility 
The solubility of oxygen and hydrogen in salt solution is about an order of magnitude lower than in pure water (see Norton and Pederson, PNL10785). For either gas, the solubility is about $0.1 \mathrm{mmols} / \mathrm{L}$ (of salt solution). The 2350 gallon column is $62 \mathrm{vol} \%$ solution, so about $13.5 \mathrm{~L}$ of gas is soluble in the solution.

$$
2350 \text { gal soln } * 0.62 * 3.7854 \frac{\mathrm{L}}{\mathrm{gal}} * 0.0001 \frac{\mathrm{mols} \text { gas }}{\mathrm{L} \text { soln }} * 24.46 \frac{\mathrm{L} \text { gas }}{\mathrm{mol} \mathrm{gas}}=13.5 \mathrm{~L} \text { gas }
$$

Generation of bubbles

At a generation rate of $33 \mathrm{~L} / \mathrm{h}$ and a solubility of about $13.5 \mathrm{~L}$, gas bubbles will form in about 30 minutes even if initially there is no gas dissolved in the salt solution.

Case 2. Fully loaded column, 20 gpm feed flow

Gas generation rate: $33 \mathrm{~L} / \mathrm{hr}$, same as Case 1.

Gas removal rate:

Assume no oxygen or hydrogen are dissolved in the feed stream. Assume the effluent stream $(20 \mathrm{gpm})$ exits the column saturated with oxygen ( 0.1 mmolar) and hydrogen ( 0.1 mmolar ). Then the rate of removal as soluble gas is:

$$
\begin{aligned}
& 20 \frac{\text { gal soln }}{\mathrm{min}} * 3.7854 \frac{\mathrm{L}}{\mathrm{gal}} 0.0001 \frac{\mathrm{mols} \text { gas }}{\mathrm{L} \mathrm{soln}} * 60 \frac{\mathrm{min}}{\mathrm{hr}} * 24.46 \frac{\mathrm{L} \text { gas }}{\mathrm{mol} \text { gas }} \\
&=11 \mathrm{~L} / \mathrm{hr} \text { removal rate for either oxygen or } \\
& \text { hydrogen }
\end{aligned}
$$

\section{Generation of bubbles}

Hydrogen will not exceed the solubility limit at $20 \mathrm{gpm}$.

Oxygen will exceed the solubility limit by more than a factor of two and bubbles will form in the column. 
HLW-SDT-99-0257

Revision: 0

5.2 ATTACHMENT 2

Page 15 of 16

Memorandum from A. Mattus on use of ORNL's HFIR reactor for gas generation study

\section{Synopsis of the Gas Generation Experiment}

Objective: To observe and document the effect of in-column gas generation during CST loading of cesium due to gamma radiolysis of soluble waste salts forming primarily oxygen gas, which if produced faster than can be solubilized and removed, may potentially blind exchange sites and result in premature breakthrough.

Cost:.A fully burdened cost of $\$ 176 \mathrm{~K}$

Schedule: Upon starting no later than July 26 a final report would be delivered on or before November 16,1999.

\section{General Description of the Proposed Experimental Setup:}

A column would be machined from stainless steel (SS) to the inner working dimensions of 1.5 (d) by $10 \mathrm{~cm}$ (1). with additional space for expansion. The column would be equipped with a water jacket containing a built in thermocouple. Both the column feed surrogate and the cooling water would be carried to and from the column through 0.25 inch SS tubing. The feed solution would enter through the top of the column where a pressure release valve would be placed in case of plugging and would serve, when opened due to high back pressure, to divert solution around the column. The four, 0.25 inch tubes leading to the jacketed column would pass through a thin walled 0.75 inch SS pipe from above the surface of the HFIR pool to the column.

Between the quarter inch tubing and the wall will be placed open-wire conductivity sensors near the column. A leak of conductive surrogate would be identified in this way. The conductivity sensors would be connected to an audible alarm for workers to respond to at the HFIR reactor. Additionally a positive displacement pump at pool side would be equipped with a calibrated transducer to activate the same audible. alarm during a pressure rise.

An equilibrated surrogate solution containing cold cesium would be pumped from a 35 gallon plastic feed tank near the side of the pool. This tank may have to be placed inside a secondary tank to contain a possible leak. The column effluent will discharge into a similar receiver tank which will rest on an electronic balance where samples can be removed for analysis.

Since the pool is at approximately $500^{\circ} \mathrm{C}$, maintaining a $25^{\circ} \mathrm{C}$ target temperature at a relatively low flow rate for passage through nearly 20 feet of pool water will require insulation. For this purpose the 0.75 inch tubing containing the four $0.25 \mathrm{SS}$ tubes will be placed inside a slightly larger SS tube which will maintain a vacuum in the annular space, with a gauge to identify leaks and thereby provide insulation. Chilled water or a glycol water mixture will be pumped into the jacket from a chiller at pool side, water will be tested first at approximately $5^{\circ} \mathrm{C}$.

This umbilical cord arrangement of SS pipe will be shaped such that it will angle 
downward into the pool such that the column rests vertically inside a 3.83 inch diameter by 20.0 inch long space inside the fuel rod. The wall surrounding the column is made from cadmium but some high energy neutrons which are expected to pass through may activate cobalt in the steel requiring a disposal consideration. The apparatus will be no wider than 3.50 inches to allow for potential expansion inside the fuel rod. The gamma field intensity is approximately $10 \mathrm{Mrad} / \mathrm{h}$ at chamber center.

\section{Precautions:}

Because of the exceedingly grave and costly consequence of even a small leak of surrogate or glycol solution into the HFIR pool and its potential affect upon the thin aluminum cladding surrounding the fuel rods, the reactor review committees will dictate strict control and oversight of the experiment. The experiment will run $24 \mathrm{~h}$ per day with full coverage by our staff. All'sensors, transducers, and gauges will have to be calibrated and all piping will be pressure and vacuum checked prior to placement in the pool. Drawings, procedures and operetion will have to be thoroughly expounded upon before committee, and all necessary paperwork put in place. It is optimistically expected that a minimum of 5 weeks will be necessary to obtain permission to start.

\section{Potential Constraints and Impediments:}

(a) Unknown levels of QA/QC applied to the work may add to cost. (b) Ongoing experiments presently in the HFIR pool may need negotiation to run our experiment preferentially inside a pre-existing user schedule. (c) The level of containment and quality control mandated by the reactor review committees. (d) It is assumed that only a minimal amount of HFIR staff time will have to be costed during the setup and operation of the experiment. (e) Other committee-required redundancies in the equipment design. (f) Space for a chiller, two tanks, pump and scale is limited at pool side and may present a need for some innovation. A rolling crane moves over the pool and its movement results in space constraints. 